\title{
Health Services for Management of Chronic Non-Cancer Pain in Kuwait: A Case Study Review
}

\author{
S. Fatima Lakha ${ }^{\text {a }}$ Peter Pennefather ${ }^{\mathrm{a}}$ Hanan E. Badr ${ }^{\mathrm{c}}$ \\ Angela Mailis-Gagnon ${ }^{a, b}$ \\ a University of Toronto and ${ }^{b}$ Comprehensive Pain Toronto, Krembil Neuroscience Centre, University Health Network, \\ Toronto, Ont., Canada; ' Department of Community Medicine and Behavioral Sciences, Faculty of Medicine, Kuwait \\ University, Safat, Kuwait
}

\section{Key Words}

Chronic non-cancer pain · Kuwaiti health system .

Pain services and management

\begin{abstract}
The experience of chronic pain is universal, yet pain management services delivered by health professionals vary substantially, depending on the context and patient. This review is a part of a series that has examined the issue of chronic non-cancer pain services and management in different global cities. The review is structured as a case study of the availability of management services for people living with chronic non-cancer pain within the context of the Kuwaiti health systems, and the cases are built from evidence in the published literature identified through a comprehensive review process. The evolution of the organizational structure of the public and private health systems in Kuwait is described. These are discussed in terms of their impact on the delivery of comprehensive chronic pain management service by health professionals in Kuwait. This review also includes a description of chronic pain patient personas to highlight expected barriers as well as compliance issues with services likely to be encountered in Kuwait. The case study analysis and persona descriptions illustrate a need to move beyond
\end{abstract}

pain symptom management towards considering the entire person and his/her individual experience of pain such that health care success is judged by enhancement of patient well-being rather than access to services. A road map for improving integrative chronic pain management in Kuwait is discussed.

(c) 2015 S. Karger AG, Basel

\section{Introduction}

Non-communicable diseases account for $59 \%$ of the world's 57 million annual deaths, and $46 \%$ of the global burden of disease $[1,2]$. The Eastern Mediterranean Region Office (EMRO) of the World Health Organization (WHO) (where Kuwait is represented) indicates that chronic diseases account for about $47 \%$ of the total burden of disease in this region [3]. Unlike communicable diseases where success can be measured in terms of cases prevented and lives saved, with chronic disease success needs to be measured in terms of promoting an experience of well-being and reducing experienced burdens of disease at the individual and population levels [1].

The challenges health systems face in dealing with chronic pain is representative of the larger challenge of

\begin{tabular}{ll}
\hline KARGER & $\begin{array}{l}\text { ○ 2015 S. Karger AG, Basel } \\
1011-7571 / 15 / 0257-0029 \$ 39.50 / 0 \quad \text { Karger }\end{array}$ \\
E-Mail karger@karger.com & $\begin{array}{l}\text { This is an Open Access article licensed under the terms of the } \\
\text { Creative Commons Attribution-NonCommercial 3.0 Un- } \\
\text { ported license (CC BY-NC) (www.karger.com/OA-license), } \\
\text { applicable to the online version of the article only. Distribu- } \\
\text { tion permitted for non-commercial purposes only. }\end{array}$
\end{tabular}

Dr. Hanan El-Sayed Badr, MD, MPH, PhD

Department of Community Medicine and Behavioral Sciences

Faculty of Medicine, Kuwait University, PO Box 24923

Safat 13110 (Kuwait)

E-Mail hanan@hsc.edu.kw 
dealing with chronic disease in general. A person's burden from chronic diseases is related to how it impairs everyday physical and mental functions and reduces his/her ability to perform activities of daily living and contribute to society and the economy. This is particularly true for people living with chronic pain [1]. Also the condition of chronic pain is an important contributor to the burden associated with living with many other chronic diseases [1].

Chronic non-cancer pain (CNCP) is usually defined as pain persisting over 3-6 months. Since chronic pain arises primarily from non-cancer causes, in this paper the terms chronic pain and $\mathrm{CNCP}$ are used interchangeably. In this narrative review we focus on management of $\mathrm{CNCP}$ and on how that management process needs to become more comprehensive as recommended by many international organizations.

Comprehensive cancer pain management is already a recognized pillar of oncology where optimal pain management is required to help patients survive their cancer despite highly invasive care [4]. CNCP on the other hand spans a wide range of conditions ranging from mild annoyance to complete incapacitation. Nevertheless, a person's experience of well-being while living with pain can be increased through coordinated interventions by medical professionals and the health care system [5]. In keeping with the wider evolution of the concept of health from an absence of disease and disease symptoms to an experience of well-being [3], this review takes a well-being perspective.

Because pain is a multivalent, dynamic, and ambiguous phenomenon, it is notoriously difficult to quantify; therefore, caution is warranted in issuing broad statements regarding the global epidemiology of chronic pain. Nevertheless, it is estimated that at least $10 \%$ of the world's population, approximately 600 million people, endure chronic pain, regardless of age, sex, income, race/ethnicity, or geography [5]. Although the prevalence of chronic pain complaints are universal, people living in economically disadvantaged countries or who are themselves economically disadvantaged exhibit higher health burdens associated with unrelieved persistent pain and less access to treatments proven to be effective [6].

This chronic pain burden is associated with economic costs that are both direct and indirect [7]. Recently, Gaskin and Richard [8] attempted to estimate the annual economic costs of chronic pain in the US in terms of direct and indirect costs. They estimated the costs range from USD 560-635 (KWD 170-192 billion), equally divided between direct and indirect costs. There are no published studies that attempt to estimate the economic burden of pain in the Arab world. However, statistics for the prevalence of pain in Kuwait are similar to its global distribution [9]. Assuming a similar estimate to the economic burden of the Kuwait gross domestic product (GDP), costs in the billions of Kuwaiti dinars can be projected.

Pain management is complicated by how it impacts a patient's health status, treatment decisions, service use, resource allocation, and costs of health care provided for other clinical reasons. If pain is not specifically treated, it will augment the burden of other co-morbidities associated with other chronic non-communicable diseases [7]. In addition, pain itself can sometimes develop into chronic disease $[10,11]$. For all of these clinical reasons, internationally and within Kuwait, there is a growing interest in redesigning health care organizations and practices to improve the quality of care for chronic pain patients. There is a recognized need to close the gap in pain management between what is known to improve outcomes and what is practiced $[12,13]$.

There are also moral and ethical issues driving advocacy for greater access to effective pain management service. The constitution of the WHO defines health as a state of complete physical, mental, and social well-being, and not merely the absence of disease or infirmity [14]. The International Society for the Study of Pain is collaborating with the WHO, both to highlight the challenge of adequately providing health care for pain-related problems and to encourage implementation within the health system of pain management services known to be effective in improving health and well-being [15]. Under international human rights law, governments must take steps to ensure that people under their jurisdiction have adequate access to treatment for their pain [16]. Over the years, several agencies have addressed inequality in both health and health care across the full spectrum of chronic diseases (including pain) $[7,17,18]$. Indeed, in 2010, the Kuwaiti government announced a program to make $\mathrm{Ku}$ wait free from pain [12]. As yet there are no published reports available on the success of that program. Globally, the gap between progressively sophisticated knowledge of pain and its treatment and the effective application of that knowledge is large $[19,20]$. Both acute and chronic pain is often poorly managed for a wide variety of cultural, attitudinal, educational, political, and logistical reasons [21, 22].

In order to understand the landscape of pain management and services available in Kuwait in a way that is comparable amongst other countries, there is a need to 
review the existing Kuwaiti health care system, organizational structure of public and private system, availability of pain management services, and barriers that often impede access to and compliance with care plans provided or recommended. This article is a combination of case study and narrative review, and includes illustrations of personas to clarify the system to the external audience. A comprehensive search process was conducted that included PubMed, Scholars Portal, Sociological Abstracts, and Google Scholar. Previous materials published in peer-reviewed journals and grey literature were reviewed in a systematic manner. References cited in relevant articles were also reviewed. In addition, in order to further explore likely impact of available pain management services in Kuwait, the present review used the lens of chronic pain patient personas living in Kuwait. Personas are defined as fictional, but specific and concrete representations of potential target users of a product or service undergoing re-design. Personas put a face on the user; a memorable, engaging, and actionable image that serves as a design target [23]. Personas are used to illustrate how the health system can accommodate different kinds of patients living with pain and to illustrate expected barriers that such patients are likely to encounter. In summary, the overall aim of this article is to provide a description of how the Kuwaiti health system deals with the challenges of CNCP pain management.

\section{Kuwaiti Health System: Background}

\section{Demographics and Geography}

Kuwait is a sovereign Arab state situated in the northeast of the Arabian Peninsula in Western Asia. Kuwait is administratively divided into 6 governorates: the capital (Kuwait), Hawali, Farwaniya, Jahra, Ahmadi, and Mobarak Al-Kabir. Kuwait's economy is based largely on oil and its per capita income is USD 23,500 (KWD 7,105), one of the highest in the world [24]. As of 2012, Kuwait's population was estimated to be 3.8 million people [25], and Kuwaiti nationals comprised $32 \%$ of the population, with males making up $49 \%$ and females $51 \%$ of this population [25]. Among non-nationals, there is a high predominance of males (65\%), who are mainly Asians (54\%) and Arabs (42\%) [26]. Most of these expatriates occupy lower occupational positions with a predominance in heavy labour jobs. There are no data about their interaction with the health system. Regardless of occupational level, most expatriates work in the private sector and are paid less for the same type of work than nationals.

Comprehensive Chronic Pain

Management in Kuwait
General Characteristics of Health Management

\section{Service in Kuwait}

Kuwait's first efforts to initiate a modern health care system date back to the first years of the twentieth century [27]. By 1911 a hospital for men was developed followed by a small one for women in 1919 [27]. After the government began receiving oil revenues, it expanded the health care system, beginning with the opening of the Amiri Hospital in 1949 [27]. General mortality remained between 20 and 25 per 1,000 population and infant mortality between 100 and 125 per 1,000 live births [27]. After independence in 1961, the government initiated a comprehensive health care system offering free services to the entire population. Expenditures on health ranked third in the national budget. Most of the physicians were foreigners, particularly Egyptians. Nonetheless, by the 1990s, improvements in national health metrics were dramatic. Life expectancy increased by 10 years as compared to just before independence, putting Kuwait at a level comparable to most industrialized countries [28].

This situation changed with the first Gulf War in 1990. The Ministry of Health $(\mathrm{MOH})$ is responsible for health policy planning, regulation, monitoring, and evaluation, as well as health care service delivery. One of the government's primary tasks after liberation was to bring the health care system back on track in the shortest possible time [29]. In recent years, the MOH has acquired modern and expensive medical equipment, mostly for instrumental treatment over prevention [30]. Nevertheless, very significant improvement in the health of the population has been achieved in the last 20 years, with Kuwait ranking in the top 50 nations globally and in the top 10\% of EMRO nations in terms of access to health services [31]. However, for pain management, further investment in education and ongoing training is required.

\section{Current Organizational Structure of Health Services}

Comprehensive health services are available in Kuwait from both public and private health care providers. There are six independent health areas (governorates) in $\mathrm{Ku}$ wait: the capital (Kuwait), Al-Sabah, Capital, Farwaniya, Hawally, Ahmadi, and Jahra. Each area is supervised centrally by the $\mathrm{MOH}$ and managed locally by a director. The health services are provided through six public and 12 private hospitals. Home visits are generally not available under the public health system, except for geriatric home visits that are offered through the primary health care centres in each health area. According to the World Bank, the total health expenditure as percentage of the GDP in 2013 was $2.89 \%$ [32]. This is far less than corresponding 
Fig. 1. Illustration of the Kuwaiti health

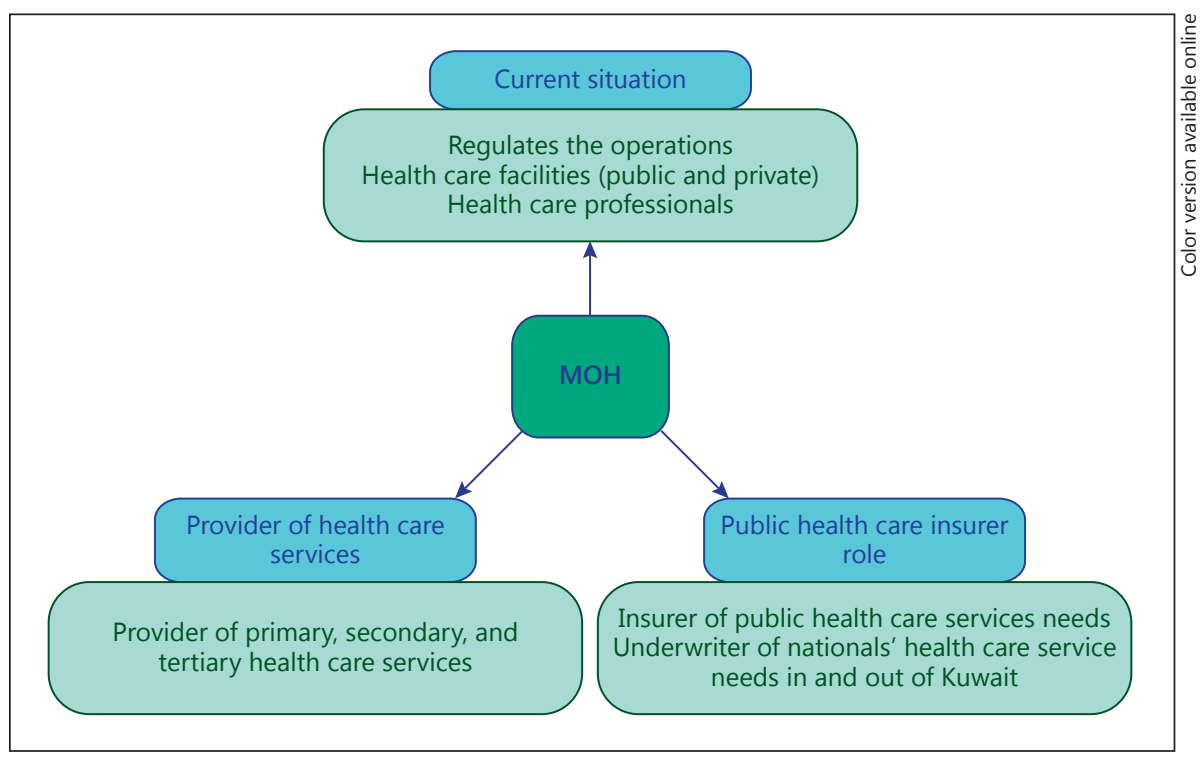
system.

rates in developed countries such as the USA (18\%) and Canada (11\%) for the same year [32].

All health services in Kuwait are provided free of charge for nationals. Non-nationals have to pay for health insurance and are expected to make a small co-payment to access primary health centres (PHCs), where they can be referred to a specialist for free. Regarding medications, some medicines are restricted for nationals, while nonnationals have to buy them from private pharmacies. The free medications are available in pharmacies affiliated with the public hospitals and are provided with a physician's prescription. Also, laboratory and radiological investigations are free for nationals, but for non-nationals it is a fee-for-service system. Since 2011, expatriates who are working in the $\mathrm{MOH}$, and their families, are treated as nationals in terms of access to health services and in coverage of procedure costs [31]. Additionally, some private workplaces offer facilitated access to health care services for their employees through the private health care sector. However, the level of this subsidy is unregulated and varies from one employer to another. The Kuwait National Health System and central role of $\mathrm{MOH}$ are described in figure 1 .

One's nationality is an essential information for any person seeking health care, which leads to discrimination in accessing some health care areas [33]. The Ministry of Defense and Kuwait Oil Company have separate hospitals for their employees. The Ministry of Social Affairs runs a senior home that provides health services to handicapped and elderly nationals [34].
Kuwait continues to rely on non-national health professionals to maintain its expanding health system. As of 2011 the proportion of Kuwaiti physicians, nurses, and dentists working in the governmental health sector reached 40,8 , and $65 \%$, respectively [35].

\section{Kuwait National Health Services System}

General management of chronic pain occurs as part of primary health care in most modern health care systems. In order to understand the barriers and opportunities for general pain management, it is important to describe the public and private system of the state.

\section{Public Health System Services}

All Kuwaitis and non-Kuwaitis have access to primary health care services. There are more than 100 PHCs across the 6 health regions that provide polyclinic services in Kuwait. These clinics deal with preliminary examinations and routine matters; when necessary, patients are referred to hospital specialists. In 2003, the distribution of regulated health care professionals in Kuwait per capita was: $19 / 10,000$ for medical doctors, $3 / 10,000$ for dentists, $3 / 10,000$ for pharmacists, $40 / 10,000$ for nurses, $21 / 10,000$ for hospital beds, and 3/10,000 for PHC units [25]. Recent health care providers' statistics for 2011 indicate that the number of physicians has increased to $23 / 10,000$. Hospital beds are reported to be at the 22/10,000 level. In 2011, PHCs covered around 17.6 million visits - two thirds of 
these visits were for Kuwaitis. National dental visits mediated through PHCs represented $55 \%$ compared to $45 \%$ of non-national dental visits [34].

Secondary care is provided through the six regional hospitals. In addition to these, there are nine specialist hospitals including maternity, infectious diseases, mental health, and cancer hospitals, bringing the total beds available to 6,703 , with total bed occupancy around $60 \%$. These hospitals utilize the largest proportion of the public health budget, despite restrained bed occupancy and high pressure on primary care services [34]. The same pattern of PHC visits is followed in hospital visits where national hospital visits by nationals outnumber the visits by nonnationals (55 vs. $45 \%$ ) [35].

\section{Private Medical Care Services}

Despite access to comprehensive services available through the $\mathrm{MOH}$, private hospitals and infirmaries have flourished in Kuwait. By 2011, the private sector provided health care services through 12 private hospitals and three hospitals belonging to the oil companies. The activities of these for-profit organizations remain regulated by the $\mathrm{MOH}$. The latter determines the general framework under which these private services are delivered, as well as the fees that the hospitals and clinics can charge for services provided. Private hospitals and clinics often have an affiliated private pharmacy and clinical laboratory attached to them. The private hospitals and clinics generally can handle most common acute, ambulatory care cases with some having specialized departments. Some of them have a limited number of special facilities such as intensive care units and surgical suites. But usually, they refer cases requiring specialized treatment to government-run facilities. The exception is dentistry; Kuwait has several private dentists and dentistry hospitals which deliver international-standard services [36].

Despite overseeing a substantial improvement in health since independence, government health policy remains focused on expanding hospital services in both the public and private sectors. This approach is costly in the long term and diverts resources that could be targeted at promoting health and well-being of the whole population and the whole person. Balancing those two complementary approaches (hospital care vs. community care) will require shifting resources from cure-focused treatments to public health programs aimed at promotion of comprehensive wellness programs and reducing the experienced burden of medical complaints $[1,37]$.

Comprehensive Chronic Pain

Management in Kuwait

\section{Health Insurance Schemes}

The current policy of health insurance came into effect in 1999. It is focused on making medically indicated procedures available and on expanding hospital-based resources needed to deliver services covered by this health insurance. An important element of this plan was the ministry's aim to lease out some of those newly constructed hospitals on a contractual basis to provide expatriates with access to medical care. Citizens do not have to pay insurance premiums [28]. From 2000, health insurance was made obligatory for expatriates. The residency permit renewal period is also linked to the period of health insurance coverage. Despite the private insurance, expatriates and their family members are still expected to make a co-payment for all services utilized [28]. Employers, either in the public or the private sector, pay the insurance premium of the employee only, while the latter has to pay the insurance premium for their spouse and children for renewal of their residency. Local group insurance often requires a minimum of 15 persons, with an annual premium of about KWD 75 per person (USD: 247.50) to cover medical expenses including pain management for both in-patient and outpatient treatments of up to KWD 5,000 (USD 16,500) per year $[28,38]$.

\section{Transient Guest Workers and Health Services}

The impact of chronic health conditions and associated disabilities, including the presence of pain-specific conditions, on labor force outputs and employee absenteeism and presenteeism are well established [39-41]. Occupational accidents and diseases are major causes of injury and deaths among guest workers in Kuwait. Reporting of occupational risks and diseases remains incomplete and negligible in the country and certain sectors are not covered at all. The available data provided on occupational accidents lacks precision [42].

Workers in Kuwait are covered by three branches of employment law: (1) Kuwaiti public sector, which covers only Kuwaiti Nationals, (2) oil sector labour law, which applies to both Kuwaiti and Gulf Arab nationals, (3) and private sector labour laws, which applies to all migrant workers regardless of whether they work in the oil industry or other industries in the private sector. In general, these laws are designed to help employees who have work-related injuries or medical conditions. Workers compensation 'benefits' include indirect coverage of access to medical care and treatment [43].

Med Princ Pract 2016;25(suppl 1):29-42 DOI: $10.1159 / 000442526$ 
There is an officially sanctioned workers' compensation system; however, the percentage of the workers receiving direct compensation is small. This is a consequence of the fact that few workplaces actually pay into that worker's compensation system [42]. Private sector law has not been an effective deterrent in reducing the number of work-related injuries and fatalities among migrant workers. Few injured workers receive any form of compensation. Retrospective government statistics show that the majority of workers involved in occupational injuries and fatalities were migrants employed in the construction industry $[44,45]$. In 2002, the Kuwaiti construction sector, which represents $7 \%$ of the total workforce in Kuwait, averaged 98 reported serious work-related injuries and 1 fatality per month. Data on direct and indirect costs of construction accidents were collected by the industry (1994-1996) and suggested that the indirect cost of workplace accidents is 17 times higher than the direct cost [46]. No data on occupational diseases in Kuwait were found through our review process.

Construction injuries comprised approximately 58\% of total occupational injuries during the same period (1994-1996). All workers were expatriates: $77 \%$ of them were unskilled and fractures at different body parts were the major type of injuries. Physical disability was the outcome of about $88 \%$ of injuries [47].

A major problem is underreporting of work-related accidents and diseases, not because of a lack of capacity to statistically analyse recorded occurrences, but rather because the system for notifying authorities about injuries is poorly implemented. This is a serious issue at the national and enterprise levels, preventing priority setting by decision makers [42]. The problem is further complicated by vagueness in the definition of the term 'injury' in the relevant International Labour Organization (ILO) and Occupational Safety and Health (OSH) documentation meant to guide national policy development [42]. The term 'injury' is proposed to cover a wide range of conditions ranging from broken bones to disabilities that cannot be easily linked to traumatic bodily damage. Also the term is focused on the event that led to the trauma and not on the disabling consequences of the injury for the injured worker involved.

\section{Magnitude of Pain Problems in Kuwait}

Chronic pain is increasingly recognized as a major health issue in Kuwait and a well-known consequence of everyday trauma, surgical procedures, and workplace ac- cidents [9]. A local survey reported a prevalence of $36 \%$ for musculoskeletal pain in females and $20 \%$ in males. Knee and lower back pain were the most frequent types of musculoskeletal pain in the survey. Most of these patients were middle aged or elderly people, and traumarelated musculoskeletal pain is the commonest source of their pain. The authors concluded that musculoskeletal pain is a major health problem among Kuwaitis and deserves intense government attention [45]. A recent study conducted among 2,443 Kuwaitis aged 50 years showed that overweight and obesity is prevalent among 81 and $46 \%$, respectively, of the study sample [48]. The same study revealed that overweight and obesity were independent risk factors for developing diabetes and osteoarthritis, which were present in 50 and $38 \%$, respectively, of the studied sample. Both of those chronic diseases are known to be associated with chronic pain [48].

Many conditions commonly associated with pain symptoms such as those resulting from motor vehicle accidents, work injuries, and osteoarthritis are recognized as major contributors to global disease burden as documented by the WHO $[49,50]$. There is little information about the quality of care or levels of suffering associated with acute pain and chronic pain symptoms in Kuwait, especially in the labour market.

In the US workforce, a range of common pain conditions have been shown to impact worker productivity [51]. Pain has been shown in small-to-medium size settings to have an impact on physical and mental health, to limit work performance, and increase absenteeism [52]. Importantly, in a joint declaration in 2004, the WHO and the International Association for the Study of Pain (IASP) now consider chronic pain as a disease and not merely a symptom. Pain is no longer seen as related to an evolving injury, but as reflecting pathophysiological changes within the nociceptive system with psychosocial responses that perpetuate the problem [53]. Even with this evidence for the relationship between self-reported general health status, chronic health conditions, and pain and labor market outcomes, there are still some major gaps in understanding the independent impact of pain on disability and interference in worker productivity. Much of the suffering, discomfort, and disability caused by injuries are cumulative and chronic. Pain is almost always an acute consequence of injury that sometimes develops into a chronic disability; however, in both cases an important element of the societal burden associated with worker injury can be linked to disturbance of individual well-being and productivity. Those disabilities are exacerbated by pain and mitigated by pain relief [19].
Lakha/Pennefather/Badr/Mailis-Gagnon 
Delivery of Chronic Pain Services

Comprehensive pain management services for patients with a CNCP condition did not exist as of 2006 [9]. However, access to pain management services began in Kuwait in 2008. In 2010, the Kuwaiti government launched a campaign called ' 365 Days, Kuwait without Pain' with the aspiration of making Kuwait pain free. The aim of the campaign was to motivate Kuwaiti hospitals to provide access to pain relief treatment for any patient living in Kuwait. They reached out and spread awareness to the people of Kuwait about pain and pain relief medication options [12]. However, there are no reports available on the impact, progress, or follow-up of the campaign.

Currently there are only five doctors registered as pain specialists in Kuwait. They are in charge of four governmental clinics. Among the six health areas in Kuwait, two pain clinics are located in the Sabah area (two specialized government hospital), one in each governmental hospital in Farwaniya, the capital, and Ahmadi. Patients who access these clinics are most likely to be referrals from the hospitals where the clinics are located. Although some hospital departments do refer patients to pain clinics, direct referral from the PHC practitioners is uncommon $[54,55]$.

In Kuwait, there is a lack of information concerning how people who suffer from chronic pain can gain access to adequate pain treatment [9]. Moreover, the majority of care providers deal with chronic pain without referral to pain specialists for evaluation or specialized care [55]. A common theme of several publications globally is the failure of many governments and health systems in general to take appropriate steps to organize, coordinate, and support access to pain treatment services $[9,56,57]$. Therefore, there is a need to identify barriers to such care and to initiate strategic plans for making chronic pain management service available and accessible in Kuwait.

\section{Expected Barriers in Delivery of Chronic Pain Management Services}

An estimated $80 \%$ of people worldwide do not receive adequate treatment for pain, and severe undertreatment for pain is an acute problem in more than 150 countries [28]. Access to pain medication is distributed unevenly among rich and poor nations and between their rich and poor populations [58]. Globally, the burden of poorly managed pain is disproportionately borne by the most vulnerable: the poor, children, the elderly, individuals with a history of substance abuse, the mentally ill, women, minorities, and people of colour [58]. This global lack of

Comprehensive Chronic Pain

Management in Kuwait pain management access by marginalized populations raises significant global health equity concerns.

The global movement towards shifting public health investments from communicable diseases to non-communicable diseases is also evident in Kuwait [59]. This reflects evidence of a trend towards increased prevalence of coronary heart disease, cancer, and accidental injuries with long-term consequences (mainly due to road traffic accidents) [60]. Many of these conditions are accompanied by chronic pain, which increases the burden of those conditions if pain is inadequately addressed and treated.

Little information is available on pain management in Kuwait. The WHO considers that barriers to access and management of chronic pain in health care systems could be financial, geographic, cultural, organizational, and sociological; however, each society has a different reality. A summary of expected barriers to the management of chronic pain in Kuwait based on existing evidence from international health reports $[4,61,62]$ is presented in table 1.

Despite the existence of a range of well-established pain management strategies, there are several obstacles to implementing effective management for chronic pain, resulting in a large proportion of patients not achieving optimal pain control [63]. These barriers to the clinical management of pain vary depending on whether they are viewed from the standpoint of the patient, the physician, or the institution. Patients are usually uncomfortable with using pain relief drugs or narcotics because of their known adverse effects, such as nausea, addiction, and respiratory arrest $[64,65]$. However, when used under clinical supervision as part of a rigorous care plan, many of these complications can be avoided. Other barriers include legal and social barriers [66]. However, there is a negative social attitude towards self-administration of morphine because of the legal barriers to access it, thus leading to a general scarcity of opiate analgesics in pharmacies [67]. There are also some barriers concerning the medical team. These include failures of doctors and nurses in evaluating and controlling a patient's pain due to fear of legal and or administrative repercussions associated with the prescriptions of even judicious uses of opiates $[68,69]$. Identification and acknowledgment of these barriers are a first step to overcoming them. Successful initiatives to overcome patient, physician, and institutional barriers need to be multifaceted and integrative. Multidisciplinary initiatives to improve pain management include dissemination of community-based information, education, and awareness programs so as to attempt to change attitudes towards pain treatment [70].

Med Princ Pract 2016;25(suppl 1):29-42 DOI: $10.1159 / 000442526$ 
Table 1. Expected barriers

\begin{tabular}{lll}
\hline Care provider-associated problems & Patient-associated problems & Health system-associated problems \\
$\begin{array}{l}\text { Lack of knowledge of the field of pain } \\
\text { management }\end{array}$ & Reservations about reporting pain & $\begin{array}{l}\text { Low priority for the treatment of non-cancer } \\
\text { pain }\end{array}$ \\
\hline $\begin{array}{l}\text { Inadequate time spent on pain } \\
\text { assessment }\end{array}$ & $\begin{array}{l}\text { Fear that pain indicates disease is getting } \\
\text { worse }\end{array}$ & $\begin{array}{l}\text { Lack of suitable remuneration policies } \\
\text { governing pain services }\end{array}$ \\
$\begin{array}{l}\text { Reservations related to regulatory } \\
\text { restrictions }\end{array}$ & $\begin{array}{l}\text { Reservations about reliance on } \\
\text { medications }\end{array}$ & $\begin{array}{l}\text { Complexity of distinguishing between abuse } \\
\text { and therapy }\end{array}$ \\
\hline Fear of addiction & Fear of addiction & $\begin{array}{l}\text { Reluctance to facilitate access to addictive } \\
\text { drugs }\end{array}$ \\
\hline $\begin{array}{l}\text { Fear of unmanageable side effects } \\
\text { Fear that tolerance will complicate } \\
\text { management }\end{array}$ & Fear of treatment complications & $\begin{array}{l}\text { Challenges of individuating pain } \\
\text { management regimes }\end{array}$ \\
$\begin{array}{l}\text { Lack of awareness of pain clinics and } \\
\text { their services }\end{array}$ & $\begin{array}{l}\text { Fack of awareness about pain clinics and } \\
\text { their services }\end{array}$ & $\begin{array}{l}\text { Lack of capacity to monitor tolerance } \\
\text { development }\end{array}$ \\
\hline
\end{tabular}

Adequate pain relief is a reasonable and achievable goal for patients once barriers to reaching that goal are recognized, addressed, and overcome.

\section{Patient Personas Illustrating Contextual Issues Influencing on Care and Compliance}

Understanding pain patients and their needs is often limited and stereotyped. One way of overcoming the lack of understanding of barriers by users when designing new ways of meeting their needs is to construct personas [71]. With the goal of imagining how chronic pain patients would fare in Kuwait, three patient personas were considered, representing different populations: (1) a Kuwaiti national, (2) a Gulf Arab national, and (3) a South Asian national. All were imagined to suffer from a similar type of chronic pain problem. Their conditions were developed by analysing publicly available accounts of patient experiences [57].

Comparison and contrasts of what the care experience of the different personas might be like with respect to benefiting from access to chronic pain management services are summarized in table 2 . One of the most important challenges faced by all three personas is availability and accessibility to comprehensive pain management services.

Several studies have reported that chronic pain is associated with an increased prevalence of anxiety or depressive disorders, especially amongst those who experience significant limitations in their daily activities due to pain (e.g. work, social activities, family life) [72-75]. Sleep disturbance, fatigue, and decreased overall functioning are also commonly experienced [76]. However, based on the existing literature, most services are often limited to monotherapy rather than offering a comprehensive multidisciplinary approach. This limited and often ineffective treatment of pain results in an escalating cascade of health care issues [77].

Certain basic interventions should be incorporated into all treatment plans, for all kind of populations. For example, significant reduction in health complications due to chronic pain usually can be achieved through therapeutic interventions such as multimodal analgesia and controlled prescription of analgesic drugs $[64,75]$. In addition, individually assessed needs, risk factors, and ability to afford recommended care must be considered. There should be regular evaluation and audit of results, outcomes, complications, and side effects of treatment for these patients.

\section{Possible Roadmap for Improving Pain Care in Kuwait}

Continued efforts are required to overcome the known barriers to effective pain management globally. Kuwait has an opportunity to lead the world in that regard because of its centralized control over health system operations and its commitment to ongoing implementations of global best practices. A general multilevel trajectory for transforming practice informed by this review is described in figure 2. At the $\mathrm{MOH}$ level, this would involve developing government policy on pain management and promotion of education programs for health care profes- 
Table 2. Case studies of patient personas

\begin{tabular}{|c|c|c|}
\hline Case 1: Kuwaiti national & Case 2: Gulf Arab national & Case 3: South Asia labourer \\
\hline $\begin{array}{l}\text { Kuwait public sector law covers only } \\
\text { Kuwaiti nationals }\end{array}$ & $\begin{array}{l}\text { The oil sector labour law applies to both } \\
\text { Kuwaiti and Gulf Arab nationals }\end{array}$ & $\begin{array}{l}\text { Private sector labour laws applies to all } \\
\text { migrant labour in the private sector regardless } \\
\text { of whether or not they work in the oil industry }\end{array}$ \\
\hline Mr X, 29 years old, Kuwait citizen & Mr Y, 29 years old, Bahrain citizen & Mr Z, 29 years old, Indian citizen \\
\hline $\begin{array}{l}\text { Present complaint: suffered lower back } \\
\text { pain } 6 \text { years ago after slipping at work as } \\
\text { a manager and has been unable to work } \\
\text { since; gradually developed antalgic gait, } \\
\text { spreading pain to his upper thigh, knees, } \\
\text { wrists and ankles }\end{array}$ & $\begin{array}{l}\text { Present complaint: suffered lower back } \\
\text { pain } 6 \text { years ago after slipping at work as } \\
\text { an employee and has been unable to } \\
\text { work since; gradually developed } \\
\text { spreading pain to his upper back, knees, } \\
\text { and wrists }\end{array}$ & $\begin{array}{l}\text { Present complaint: suffered lower back pain } 6 \\
\text { years before after slipping at work as a } \\
\text { painter, unable to work since; gradually } \\
\text { developed spreading pain to his upper back } \\
\text { and knees }\end{array}$ \\
\hline $\begin{array}{l}\text { Associated complaints: fragmented sleep, } \\
\text { weight gain, depression, very high } \\
\text { disability }\end{array}$ & $\begin{array}{l}\text { Associated complaints: fragmented sleep, } \\
\text { weight gain, very high disability }\end{array}$ & $\begin{array}{l}\text { Associated complaints: fragmented sleep, } \\
\text { irritable, and high degree of disability }\end{array}$ \\
\hline $\begin{array}{l}\text { Assessment: } \mathrm{O} / \mathrm{E} \text { looks despondent, } \\
\text { sweaty, dishevelled, sleepy, and asked to } \\
\text { lie down, with multiple verbal and } \\
\text { nonverbal pain behaviours, with hand } \\
\text { shaking and very limited range of } \\
\text { lumbosacral spine movements; rated pain } \\
10 / 10\end{array}$ & $\begin{array}{l}\text { Assessment: } \mathrm{O} / \mathrm{E} \text {, he was an overweight } \\
\text { de-conditioned man who dozed off } \\
\text { constantly but sat comfortably during } \\
\text { most of the interview despite } 8 / 10 \text { pain } \\
\text { ratings }\end{array}$ & $\begin{array}{l}\text { Assessment: } \mathrm{O} / \mathrm{E} \text { looks despondent, with } \\
\text { verbal and non-verbal pain behaviours, rated } \\
\text { pain } 13 / 10 \text {; his gait was normal, although } \\
\text { intermittently appeared antalgic favouring } \\
\text { the right leg; he is able to stand on his heels } \\
\text { and toes without difficulty; he has limited } \\
\text { ability to do a } 50 \% \text { squat due to a weak left leg }\end{array}$ \\
\hline
\end{tabular}

sionals in Kuwait on pain assessment and management. The ministry could also be involved in mobilizing and empowering the broader public and political leadership on the need and benefits of managing avoidable pain disability. Given the limited number of pain specialists in Kuwait, other health professionals have a crucial role to play in implementing innovative comprehensive care solutions supported by a rich evidence base. Support for greater continuity of care tracking and communication would ensure that quality of care increases with increasing pain management coverage [78]. The third level of the roadmap focuses on the broader networks of community groups and populations as stakeholders of the deployment of chronic pain services. This requires engagement of community representatives in building broad-based awareness of personal, social, and economic benefits of better and more comprehensive pain management. It would also involve community-level, bottom-up surveil- 
Fig. 2. Trajectory for integrating management of chronic care.

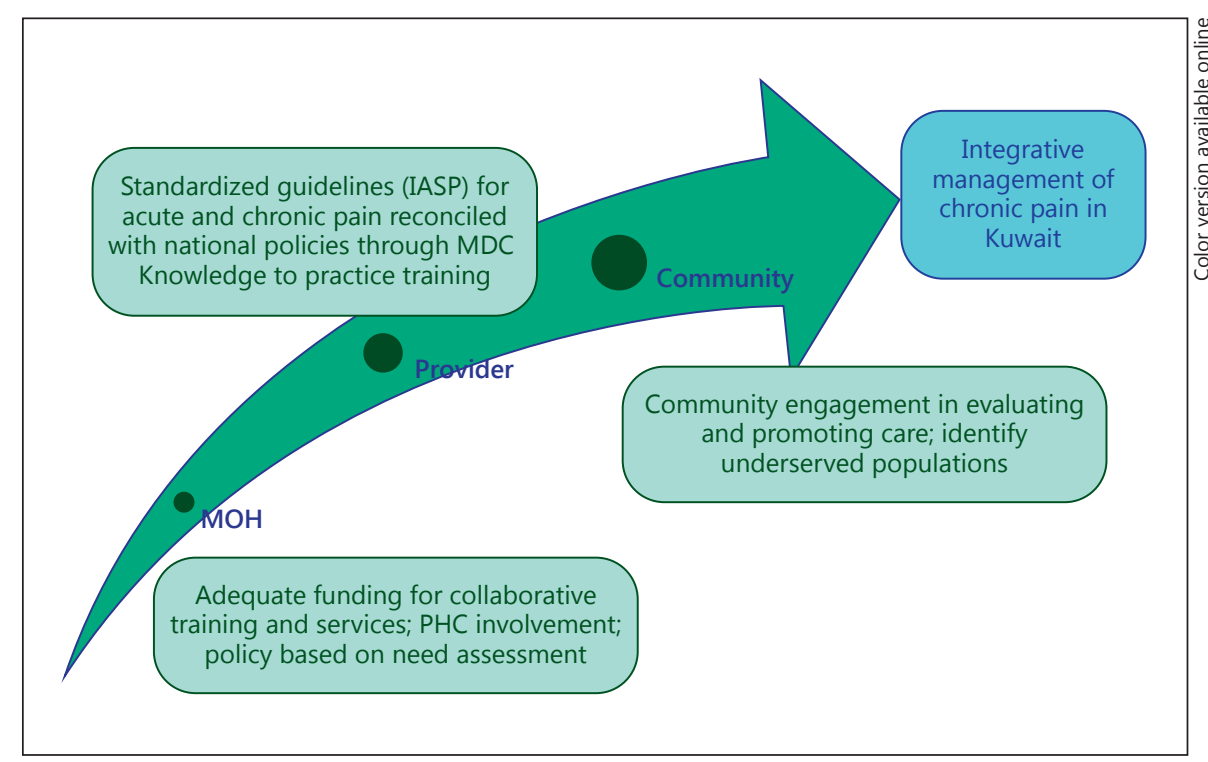

lance of the diversity of patients' experiences. Advocacy for reducing the disabling effects of pain through better pain management would become embedded in all parts of the health system delivering care.

In addition, the descriptions and recommendations set forth in this article can serve as a guide for clinicians, educators, administrators, and governmental or professional organizations involved in the establishment and maintenance of standards for pain treatment services in Kuwait. The proposed recommendations as set below reflect guidance documents as published by international associations and are supported by a synthesis and analysis of the current literature [79-84]. The goal of this review was to examine the case of Kuwait and how it relates to international efforts to reduce the global burden of avoidable disability due to pain. The way in which $\mathrm{Ku}-$ wait rises to this global challenge locally will be globally significant.

\section{Recommendations}

While there is a consensus that more integrated and adaptable health system practices are key to achieving improved health outcomes, there is less agreement on how to build these dynamic characteristics into the system. What follows are recommendations based on this case study about what needs to be considered if effective and safe management of chronic pain is to be achieved in $\mathrm{Ku}$ wait.

\section{Recognition and Awareness of the Magnitude of the}

\section{Chronic Pain Problem}

By raising awareness of the problem of a lack of organized chronic pain management services and general access to acute pain relief in Kuwait, we can begin to change practices and expectations would be changed. Thus, further desirable changes include enhancing the capacity of primary health care practitioners to provide direct care to chronic pain patients, putting in place appropriate strategies to avoid transition of acute to chronic pain, and providing adequate resources to support and expand existing specialized centres for chronic pain management as documented in the WHO study in primary care [85].

\section{Chronic Pain Care Delivery}

All personnel likely to be involved in chronic pain management should be adequately instructed in the complex nature of pain and the need for comprehensive care. Multidisciplinary team work is central to successful pain management [86]. Such training should include communication skills, the use of assessment techniques, the application of appropriate management strategies, and the use of relevant equipment appropriate for the level of resources found in the country $[87,88]$. Of paramount importance is the introduction of pain management instruction in medical schools and other programs that train health professionals who could become involved in the comprehensive care [89]. Several organizations have produced comprehensive educational package protocols and guidelines for clinical practice, including IASP (www. 
iasp-pain.org) [81, 89-92]. However, these items must be adapted to be culturally appropriate.

\section{Financial and Research Resources}

Adequate funding is required for equipment, facilities, clinical research on pain, consultants specializing in pain management, allied health care professionals, and secretarial and administrative staff. In addition, funding should be provided for all educational activities including funding for training in advanced degrees related to pain science $[93,94]$. Whenever appropriate, the educational activities should be integrated into those of interrelated departments [95].

\section{Policy, Governance, and Standardization}

Provision of core services for chronic pain management is necessary in general and specialist hospitals. Specialized pain management services should be organized locally and regionally. Formal links should be established between hospitals on a regional basis so that all appropriate treatments could be offered to patients who need them [96]. Stakeholders should collaborate to develop, implement, and evaluate guidelines for best practices for the commonest chronic pain problems [92]. While recognizing the need to regulate opioid usage [97], authorities must strive to develop national policies and systems that enable patients to safely access opioid pain medicines when needed. That access will, of course, need to be coupled with well thought out and tightly managed systems for sourcing, storing, tracking, and overseeing use of the opioid medications while providing access to training regarding opioid use, misuse, and reactions $[98,99]$. Encouraging links between countries could lead to the sharing of ideas and problems; exchange visits of personnel to developed countries would also help. Availability of vaccines with proven efficacy against pain-inducing conditions (i.e. against shingles and post-herpetic neuralgia) can substantially reduce the prevalence of these conditions in certain populations [100]. Successful implementation of opioid-based therapy for $\mathrm{CNCP}$ has been reported in many developed countries [97, 101].

\section{Special Consideration for Vulnerable Populations}

When assessing chronic pain in vulnerable populations that face social and cultural barriers to effectively communicate their experience of pain, the use of visual representation of levels of pain has been reported to be helpful [93]. When assessing and treating chronic pain, the clinician should consider non-medical features, including age, sex, and lifestyle in Kuwait. There is a need

Comprehensive Chronic Pain

Management in Kuwait to understand the complex socioeconomic, cultural, psychological, and political factors in Kuwait in order to properly develop a standard approach to pain management. Practices need to be adapted to accommodate the complex ways that the experience of pain and responsiveness to pain management are influenced by the surrounding sociocultural context $[64,102]$.

\section{Better Surveillance of Preventable Causes of Chronic Pain}

Given the importance of guest workers in the Kuwait, there is a need for the National Labor Force and Patient Registry to track the incidence of occupational injuries on sites, health trends in the population, improve the ability to prevent, treat diseases, and contribute to health care development for expatriates. Such a registry could provide a clearinghouse for data needed to reduce occupational injuries, and in doing so reduce one important cause of chronic pain. The registry could include information on all the incidents, injuries, and finalized treatments in inpatient care, data on patients who were hospitalized in the emergency trauma and pain management care, and data on patients treated by physicians in nonprimary care venues and measures for patients who received comprehensive care. The data could then support research and evaluation of practices that contribute to or reduce the burden of workplace injuries.

\section{Conclusions}

Kuwait has invested heavily in establishing one of the most modern health care infrastructure systems in the region. The health system consists of both public and private sectors. The bulk of health services are provided by the public sector through the $\mathrm{MOH}$. Equitable access to chronic pain management services is needed for expatriates resident in the country to provide effective relief of pain resulting from occupational injuries. In contrast to countries such as the United States and Australia, there are no estimates in the Mediterranean Eastern Region of the national impact of the severity and frequency of pain symptoms on labour force participation, absenteeism, and presenteeism.

This review described ways in which pain management is being addressed across the health system in $\mathrm{Ku}$ wait among the different populations.

While there is an international consensus that integrated health systems of treating the whole patient include pain and suffering as keys to achieve improved 
health outcomes, there is less agreement on how to achieve these goals. The problem of undertreatment of CNCP pain is extensive in Kuwait and provides a focus for achieving comprehensive care. Until undertreatment of chronic pain is considered a health issue, a significant percentage of people using the Kuwaiti health system will continue to suffer from chronic pain and the numbers will only increase. These patients may be undertreated or not treated at all. This deficit of care is reflected in a dearth of CNCP specialists and specialized pain clinics. This situation is likely the result of a lack of awareness of the ability to manage chronic pain and of the consequences of not adequately managing the condition. Equitable access to proper pain management in Kuwait could improve the quality of life for all patients as well as make it easier for health care providers to do their job.

\section{References}

1 Global Status Report on Non-Communicable Diseases. Description of the Global Burden of NCDs, Their Risk Factors and Determinants. Geneva, World Health Organization, 2010. http://www.who.int/nmh/publications/ncd report_full_en.pdf.

2 Lozano R, Lozano R, Naghavi M, et al: Global and regional mortality from 235 causes of death for 20 age groups in 1990 and 2010: a systematic analysis for the Global Burden of Disease Study 2010. Lancet 2012;380:20952128.

3 Preventing Chronic Diseases. A Vital Investment: WHO Global Report. Geneva, World Health Organization, 2005.

4 Sapir R: Guide to Pain Management. Washington, US Department of Health and Human Services and the Middle East Cancer Consortium, 2010. http://www.palliative.kz/uploads/ user_5/2014_15_07_05_14_33_832.pdf.

5 Unrelieved pain is a major global healthcare problem. Washington, International Association for the Study of Pain, 2013. http://www. iasp-pain.org/Advocacy/Content. aspx?ItemNumber $=1305$.

6 Goldberg DS, McGee SJ: Pain as a global public health priority. BMC Public Health 2011; 11:770.

7 Reflection Process on Chronic Diseases in the EU - The Role of Chronic Pain, Systematic Literature Report. Diegem, European Federation of IASP ${ }^{\circledR}$ Chapters, 2012. http://www. sip-platform.eu/tl_files/redakteur-bereich/ Home/ReflectionProcess_screen.pdf.

8 Gaskin DJ, Richard P: The economic costs of pain in the United States. J Pain 2012;13:715724.

9 Hadi I: Chronic pain clinic in Kuwait: are we prepared? KMJ 2006;38:169-170.

10 Ronksley PE: Unmet Health Care Needs and Adverse Outcomes for Patients with Chronic Disease; thesis, University of Calgary, Calgary, 2013. http://theses.ucalgary.ca/bitstream/11023/565/2/ucalgary_2013_ronksley_paul.pdf.

11 Witkin L Farrar JT, Ashburn MA: Can assessing chronic pain outcomes data improve outcomes? Pain Med 2013;14:779-791.

12 Pain Free Kuwait: Ministry of Health. 2010. http://www.painfreekuwait.org/.
13 Erdek MA, Pronovost PJ: Improving assessment and treatment of pain in the critically ill. Int J Qual Health Care 2004;16:59-64.

14 Constitution of the World Health Organization as adopted by the International Health Conference, New York, 19-22 June, 1946; signed on 22 July 1946 (Official Records of the World Health Organization, No. 2, p. 100) and entered into force on 7 April 1948. 2014. http://www.who.int/about/definition/en/ print.html.

15 Bond M, Breivik H: Why pain control matters in a world full of killer diseases. Clinical updates. Pain 2004;12:1-4.

16 Lohman D, Scheifer R, Amon JJ: Access to pain treatment as a human right. BMC Med 2010;8:8.

17 Campbell LC, Robinson K, Meghani SH, et al: Challenges and opportunities in pain management disparities research: implications for clinical practice, advocacy, and policy. J Pain 2012;13:611-619.

18 Halpin HA, Morales-Suárez-Varela MM, Martin-Moreno JM: Chronic disease prevention and the New Public Health. Public Health Rev 2010;32:120-154.

19 Patel NB: Physiology of Pain: Guide to Pain Management in Low-Resource Settings. Seattle, International Association for the Study of Pain, 2010, pp 13-18.

20 Schott GD: Exploring the visual hallucinations of migraine aura: the tacit contribution of illustration. Brain 2007;130:1690-1703.

21 Brennan F, Cousins MJ: Pain relief as a human right. Pain 2004;125:1-4.

22 Loeser JD: Economic implications of pain management. Acta Anaesthesiol Scand 1999; 43:957-959.

23 Adlin T, Pruitt J: The Essential Persona Lifecycle. Amsterdam, Morgan Kaufmann, 2010

24 Al-Ansari H, Al-Enezi S: Health sciences libraries in Kuwait: a study of their resources, facilities, and services. Bull Med Libr Assoc 2001;89:287-293.

25 Public Authority for Civil Information (Kuwait). 2013. https://www.paci.gov.kw/Home. aspx.

26 Public Authority for Civil Information (Kuwait). 2012. https://www.paci.gov.kw/Home. aspx.
27 Metz HC: Persian Gulf States: A Country Study. Washington, GPO for the Library of Congress, 1993. http://countrystudies.us/persian-gulf-states/.

28 Health System Profile - Kuwait. Geneva, Regional Health System Observatory World Health Organization (EMRO), 2006, pp 1-63. http://apps.who.int/medicinedocs/en/d/ Js17297e/.

29 Health System Profile - Kuwait. Geneva, Regional Health System Observatory WHO Report, 2006, p 18. http://apps.who.int/medicinedocs/documents/s17297e/s17297e.pdf.

30 Mortimer LR: Kuwait: A Country Study, 2004. World Public Edition by Federal Research Division, Blackmask Online Collection Publisher, 83.

31 World Health Statistics 2012: WHO Library Cataloguing-in-Publication Data. 2012. http:// apps.who.int/iris/bitstream/10665/44844/ 1/9789241564441_eng.pdf.

32 Credit Suisse: Global Wealth Overview. 2013. https://publications.credit-suisse.com/ ta sks/render/file/index.cfm? fileid=88EE6EC8-83E8-EB92-9D5F39D$5 \mathrm{~F} 5 \mathrm{CD} 01 \mathrm{~F} 4$

33 Shah NM, Shah MA, Behbehani J: Ethnicity, nationality and health care accessibility in $\mathrm{Ku}$ wait: a study of hospital emergency room users. Health Policy Plan 1996;11:319-328.

34 Kronfol N, Mehio Sibai A, Rizk A: Ageing in the Arab Region: Trends, Implications and Policy Options, 2013. Beirut, ESCWA, 2014. http://www.escwa.un.org/divisions/div_editor $/$ Download.asp?table_name $=$ divisions other\&field_name $=$ ID\&FileID $=1588$.

35 Health Kuwait, 2011. Department of Health Information \& Medical Records Ministry of Health, State of Kuwait. Edition XLVIII. 2011. http://www.moh.gov.kw/all.htm.

36 Public Authority for Civil Information (Kuwait). 2010. https://www.paci.gov.kw/Home. aspx.

37 Shukri K: The Challenges \& Solutions of Reforming Kuwait's Health-Care System, Kuwait: Health Reform 2009 Conference, 2009. http://1063991164.n39099.test.prositehosting.co.uk/Magazine.pdf 
38 Eastern Mediterranean Status Report on Road Safety: Call for Action. Cairo, Regional Office for the Eastern Mediterranean, WHO, 2010. http://applications.emro.who.int/dsaf/ dsa1045.pdf.

39 Langley P, Müller-Schwefe G, Nicolaou A, et al: The impact of pain on labour force participation, absenteeism and presenteeism in the European Union. J Med Econ 2010;13: 662-672.

40 Bansback N, Zhang W, Walsh D, et al: Factors associated with absenteeism, presenteeism and activity impairment in patients in the first years of RA. Rheumatology 2012;51:375-384.

41 Zhang X, Zhao X, Harris A: Chronic diseases and labour force participation in Australia. J Health Econ 2009;28:91-108.

42 Overview of the Occupational Safety and Health Situation in the Arab Region. InterRegional Tripartite Meeting on Occupational Safety and Health. 2007. http://www.google. $\mathrm{ca} / \mathrm{url}$ ? $\mathrm{sa}=\mathrm{t} \& \mathrm{rct}=\mathrm{j} \& \mathrm{q}=\&$ esrc $=\mathrm{s} \&$ source $=$ web $\& c d=1 \& v e d=0 C B 4 Q F j A A \& u r l=h t t p \% 3 A \% 2$ F\%2Fwww.oicvet.org\%2Ffiles\%2Fpilot-alo_ study_en .d oc \& e i $=3$ m KMV a n w Mcu-ggTkpruoBg\&usg=AFQjCNGvbrkrig0 ksCw35idnJvDSUF1xHg\&sig2=_Zx40msGWuUp6SsYPwnjuA.

43 Sargeant M, Giovannone M: Vulnerable Workers: Health, Safety, and Well-Being. 2011. Farnham, Gower Publishing, 2011. http://samples.sainsburysebooks.co. uk/9781409426639_sample_948996.pdf.

44 Robertson C, Lamm F: Occupational health and safety in the Kuwait construction industry: the rationale for research. Labour, Employment and Work in New Zealand 2008, pp 370-376.

45 Al-Tabtabai HM: Analyzing construction site accidents in Kuwait. Kuwait J Sci Eng 2002;29: 3-15.

46 Kartam NA, Bouz RG: Fatalities and injuries in the Kuwaiti construction industry. Accid Anal And Prev 1998;30:805-814.

47 Zawilla N, Badr H, Al Shatti A: Non-fatal occupational injuries and disability in construction workers in Kuwait 2003-2005. Egypt J Occup Med 2008;32:43-61.

48 Badr H, Shah NM, Shah MA: Obesity among Kuwaitis aged 50 years or older: prevalence, correlates and comorbidities, 2013. Gerontologist 2013;53:555-566.

49 Murray CJL, Richards M, Newton JN, et al: UK health performance: findings of the Global Burden of Disease Study 2010. Lancet 2013; 381:997-1020.

50 Health statistics and health information systems: Global Burden of Disease (GBD), WHO. 2013. http://www.who.int/healthinfo/ statistics/GlobalDALYmethods _2000_2011. pdf.

51 Stewart W, Ricci JA, Chee E, et al: Cost of lost productive work time among US workers with depression. JAMA 2003;289:3135-3144.
52 Allen H, Hubbard D: The burden of pain on employee health and productivity at a major provider of business services. J Occup Environ Med 2005;47:658-670.

53 Niv D, Devor M: Chronic pain as a disease in its own right. Pain Pract 2004;4:179-181.

54 Al-Doghaither AH, Abdelrhman BM, Saeed AA, et al: Patients' satisfaction with primary health care centers services in Kuwait City, Kuwait. J Family Community Med 2001;8: 59-65.

55 World Health Survey in Kuwait: Main Report 2013. Kuwait City, Ministry of Health, 2013, p 404. https://www.moh.gov.kw/Renderers/ ShowPdf.ashx?Id=69bfb7fe-9432-4029-bc6ed320b3aa353e.

56 Communicable Diseases in Eastern Mediterranean Region: Prevention and Control 2010-2011 report / World Health Organization. Cairo, Regional Office for the Eastern Mediterranean. 2012. http://applications. emro.who.int/dsaf/EMRPUB_2012_EN_ 766.pdf.

57 Health insurance burden: expats 'no substantial returns despite paying big sum'. Arab Times, 2013. http://www.arabtimesonline. com/NewsDetails /tabid/96/smid/414/ArticleID/181161/reftab/96/ (accessed 2015).

58 Sullivan LW, Eagel BA: Leveling the playing field: recognizing and rectifying disparities in management of pain. Pain Med 2005;6:5-10.

59 Zurayk H, Giacaman R, Jabbour S, et al: The making of the Lancet Series on health in the Arab world. Lancet 2014;383:393-395.

60 Institute for Health Metrics and Evaluation Kuwait (GBD) Report. Seattle, University of Washington, 2010. http://www.healthdata. org/sites/default/files/files/country_profiles/ GBD/ihme_gbd_country_report_kuwait. pdf.

61 Global State of Pain Treatment: Access to Medicines and Palliative Care. New York, Human Rights Watch, 2011. http://www.hrw. $\mathrm{org} / \mathrm{sites} /$ default/files/reports/hhr0511W. pdf.

62 Soyannwo OA: Obstacles to Pain Management: Guide to Pain Management in LowResource Settings. Washington, IASP, 2010, pp 9-11. http://www.iasp-pain.org/files/Content/ContentFolders/Publications2/Free Books/Guide_to_Pain_Management_in Low-Resource_Settings.pdf.

63 Upshur CC, Luckmann RS, Savageau JA: Primary care provider concerns about management of chronic pain in community clinic populations. J Gen Intern Med 2006;21:652655.

64 Albaqawi H: Pain Mangement in Hail Region Hospitals in Saudi Arabia; thesis 2014, School of Health Sciences College of Science, Engineering and Health, RMIT University, Melbourne, 2014. https://researchbank.rmit.edu. au/eserv/rmit:160757/Albaqawi.pdf.

65 Lee KF, James BR, Geoffrey PD: Chronic pain management and the surgeon: barriers and opportunities. J Am Coll Surg 2001;193:689701.
66 Borneman T, Koczywas M, Sun VC, et al: Reducing patient barriers to pain and fatigue management. J Pain Symptom Manage 2010; 39:486-501.

67 Silbermann M, Arnaout M, Daher M, et al: Palliative cancer care in Middle Eastern countries: accomplishments and challenges. Ann Oncol 2012;23:15-28.

68 Namukwaya E, Leng M, Downing J, et al: Cancer pain management in resource-limited settings: a practice review. Pain Res Treat 2011;15:393-404.

69 Narayan MC: Culture's effects on pain assessment and management. Am J Nurs 2010;110: 38-47.

70 Zuccaro SM, Vellucci R, Sarzi-Puttini P, et al: Barriers to pain management. Clin Drug Investig 2012;32:11-19.

71 Nielsen L: Personas; in Soegaard, Rikke Friis (eds): The Encyclopedia of Human-Computer Interaction, ed 2. Aarhus, Interaction Design Foundation, 2013. https://www.interaction-design.org/encyclopedia/personas.html.

72 Cunha AC, Burke TN, Franca FJ, et al: Effect of global posture re-education and of static stretching on pain, range of motion and quality of life in women with chronic neck pain: a randomized clinical trial. Clinics (São Paulo) 2008;63:763-770.

73 Bair MJ, Wu J, Damush TM, et al: Association of depression and anxiety alone and in combination with chronic musculoskeletal pain in primary care patients. Psychosom Med 2008; 70:890-897.

74 Castro MC, Quarantini LC, Daltro C, et al: Comorbid depression and anxiety symptoms in chronic pain patients and their impact on health-related quality of life. Rev Psiq Clín 2011;38:126-129.

75 Donatella M, Mugnai F, Vivarelli L, et al: Pain and psychiatry: a critical analysis and pharmacological review. Clin Pract Epidemiol Ment Health 2006;2:1-11.

76 Turk DC, Dworkin RH, Revicki D, et al: Identifying important outcome domains for chronic pain clinical trials: an IMMPACT survey of people with pain. Pain 2008; 137 : 276-285.

77 Carter J, Watson AC, Sminkey PV: Pain management: screening and assessment of pain as part of a comprehensive case management process. Prof Case Manag 2014;19:126-134.

78 Peabody JW, Taguiwalo MM, Robalino DA, et al: Improving the quality of care in developing countries; in Jamison DT, Breman JG (eds): Disease Control Priorities in Developing Countries, ed 2. Washington, World Bank, 2006, chapter 70, p 1293.

79 International Association for the Study of Pain, Human Rights Watch, IASP, 2009. http://www.hrw.org/reports/2009/03/02/ please-do-not-make-us-suffer-any-more-0.

80 International Association for the Study of Pain 2011 Annual Report. Washington, IASP, 2011. http://www.iasp-pain.org/files/Content/ContentFolders/AboutIASP/IASPAnnualReport2011.pdf. 
81 Practice guidelines for chronic pain management: an updated report by the American Society of Anesthesiologists Task Force on Chronic Pain Management and the American Society of Regional Anesthesia and Pain Medicine. Anesthesiology 2010;112:810-833.

82 Ayad AE, Ghaly N, Ragab R, et al: Expert panel consensus recommendation for the pharmacological treatment of acute pain in the Middle East region. J Int Med Res 2011;39: 1123-1141.

83 Pain Treatment Services: Adopted by IASP 2009. Washington, IASP, 2009. http://www. iasp-pain.org/Education/Content. aspx?ItemNumber $=1381$.

84 Desirable Characteristics of National Pain Strategies: Recommendations by the International Association for the Study of Pain. Washington, IASP, 2011. http://www.iasppain.org/files/Content/NavigationMenu/Advocacy/DesirableCharacteristics_Nov2011. pdf.

85 Gureje O, Von Korff M, Simon GE, et al: Persistent pain and well-being: a World Health Organization Study in Primary Care. JAMA 1998;280:147-151.

86 Dysvik E, Vinsnes AG, Eikeland OJ: The effectiveness of a multidisciplinary pain management programme managing chronic pain. Int J Nurs Pract 2004;10:224-234.

87 McQuay HJ, Moore RA, Ecceleston C, et al: Systematic review of outpatient services for chronic pain control. Health Technol Assess 1997;1:1-135.
88 Morley S, Eccleston C Williams AC: Systematic review and meta-analysis of randomized controlled trials of cognitive behaviour therapy for chronic pain in adults, excluding headache. Pain 1999;80:1-13.

89 Kopf A, Patel Nilesh B: Guide to Pain Management in Low-Resource Settings 2010. Washington, IASP, 2010, http://www.iasppain.org/files/Content/ContentFolders/Publications2/FreeBooks/Guide_to_Pain_Management_in_Low-Resource_Settings.pdf.

90 Childs JD, Cleland JA, Elliott JM, et al: Neck pain: clinical practice guidelines linked to the International Classification of Functioning, Disability, and Health from the Orthopaedic Section of the American Physical Therapy Association. J Orthop Sports Phys Ther 2008; 38:A1-A34.

91 Pain Management Guideline. Hamilton, Health Care Association of New Jersey, 2006. http://www.hcanj.org/files/2013/09/hcanjbp_painmgmt2_3.pdf.

92 Guidelines for Pain Management Programmes for Adults. London, British Pain Society, 2013. https://www.britishpainsociety. org/static/uploads/resources/files/pmp2013 main_FINAL_v6.pdf.

93 Pain Management Services: Good Practice. London, RCoA and Pain Soc, 2003, pp 9-17.

94 Services for patients with pain. Clinical Standards Advisory Group (CSAG). London, DH, 2000. http://webarchive.nationalarchives. gov.uk/20031124063333/http://www.doh. gov.uk:80/NSF/olderpeople/ongoingworkkeyareas.pdf.
95 Dubrowski A, Morin MP: Evaluating pain education programs: an integrated approach. Pain Res Manag 2011;16:407-410.

96 Guidance on the Provision of Anesthetic Services for Chronic Pain Management. London, The Royal College of Anaesthetists, 2009. http://www.nationalpainaudit.org/ media/files/GPAS-Chronic.pdf

97 Furlan AD, Reardon R, Weppler C: Opioids for chronic non-cancer pain: a new Canadian practice guideline. CMAJ 2010;182 923-930.

98 World Health Organization: Cancer Pain Relief: With a Guide to Opioid Availability, ed 2. Geneva, WHO, 1996, pp 13-36.

99 McPherson ML: Demystifying opioid conversion calculations: a guide for effective dosing. 2011 update. Bethesda, American Society of Health-System Pharmacists, 2011, pp xiii-xxviii.

100 Harpaz R, Ortega-Sanchez IR Seward JF; Advisory Committee on Immunization Practices (ACIP) Centers for Disease Control and Prevention (CDC): Prevention of herpes zoster: recommendations of the Advisory Committee on Immunization Practices (ACIP). Recomm Rep 2008;57:1-30.

101 Jay GW: Chronic narcotic therapy for patients with chronic non-malignant pain. Eur Neurol Dis 2006;1:39-43.

102 Parris WCV: Chronic pain management Med Princ Pract 1994-1995;4:57-67. 